\title{
Intracranial hypotension and hypertension: reversible Chiari malformation due to dynamic cerebrospinal fluid abnormalities in Gorham-Stout disease. Case report
}

\author{
${ }^{*}$ Shoko Yoshimoto, MD, ${ }^{1}$ Keisuke Takai, MD, PhD, ${ }^{1}$ Koichi Takahashi, MD, PhD, ${ }^{2}$ Toshio Yasui, MD, ${ }^{3}$ \\ and Makoto Taniguchi, MD, PhD'
} Departments of ${ }^{1}$ Neurosurgery and ${ }^{3}$ Neurology, Tokyo Metropolitan Neurological Hospital; and ${ }^{2}$ Department of Neurosurgery,
Sanno Hospital, Tokyo, Japan

\begin{abstract}
Gorham-Stout disease (GSD) is an intractable disease characterized by massive osteolysis caused by abnormal lymphangiogenesis in bone. In rare cases of GSD, CSF abnormalities develop. The authors present the case of a 19-year-old woman with GSD presenting with orthostatic headache due to intracranial hypotension $\left(5 \mathrm{~cm} \mathrm{H}_{2} \mathrm{O}\right)$. The clinical course of this case was very unusual. Orthostatic headache was associated with a CSF leak from the thigh after pathological fractures of the femur and pelvis. The chronic CSF leak led to acquired Chiari malformation (CM) with syringomyelia. After an epidural blood patch, her neurological status improved; however, after the complete arrest of the CSF leak from the thigh, she presented with severe nonpostural headache and progressive visual acuity loss with optic papilledema. A ventriculoperitoneal shunt was placed to treat intracranial hypertension $\left(50 \mathrm{~cm} \mathrm{H}_{2} \mathrm{O}\right)$. Headache improved and optic papilledema decreased after shunt surgery. This case shows that dynamic CSF abnormalities may lead to reversible CM in patients with GSD. Sealing a CSF leak rather than performing suboccipital decompression is recommended for acquired CM resulting from a CSF leak.
\end{abstract}

https://thejns.org/doi/abs/10.3171/2018.5.PEDS1859

KEYWORDS massive osteolysis; lymphangiogenesis; CSF leakage; epidural blood patch; rebound intracranial hypertension; ventriculoperitoneal shunt; hydrocephalus; Chiari

$\mathrm{G}$ ORHAM-STOUT disease (GSD) is a rare intractable disease characterized by vanishing bone. ${ }^{13}$ In osteolytic bone, lymphangiogenesis, the proliferation of abnormal lymphatic vessels, is observed in histopathological examinations. ${ }^{10}$ Most patients presenting with GSD are children and young adults. The skull, clavicle, ribs, spinal vertebrae, pelvis, and femur are commonly involved. Presentation varies and depends on the sites involved. Thoracic involvement including chylothorax is a risk factor for a poor prognosis. The treatments for GSD include medication, radiation, and surgery: systemic medication includes bisphosphonate, vitamin $\mathrm{D}$, interferon, bevacizumab, and steroids. Recently, a clinical trial tested the efficacy of the mammalian target of the rapamycin inhibitor (sirolimus) for several vascular anomalies, including GSD, ${ }^{6}$ and radiation and surgical treatments are indicated for the symptomatic skeletal lesions. ${ }^{13}$ However, no standard treatments have yet been established for GSD because the mechanisms underlying the development of osteolysis with lymphangiogenesis remain unknown. Very rare cases of GSD develop abnormalities in CSF pressure. ${ }^{1-3,5,7-9,11,12,14-16,18}$ In most cases, involvement of the skull base or spinal bone causes a CSF leak. In this paper we present the first case of a patient with GSD complicated by reversible Chiari malformation $(\mathrm{CM})$. The association between CSF abnormalities (intracranial hypotension and hypertension) and acquired CM is discussed.

\section{Case Report}

History

At the age of 2 years, this patient initially presented to another hospital with pathological fractures in the right thigh. At age 7, she underwent the implantation of an artifi-

ABBREVIATIONS $\mathrm{CM}=$ Chiari malformation; EBP = epidural blood patch; $\mathrm{GSD}=$ Gorham-Stout disease .

SUBMITTED January 29, 2018. ACCEPTED May 15, 2018.

INCLUDE WHEN CITING Published online August 3, 2018; DOI: 10.3171/2018.5.PEDS1859.

* $\mathrm{S}$. Yoshimoto and K. Takai contributed equally to this work. 
Yoshimoto et al.

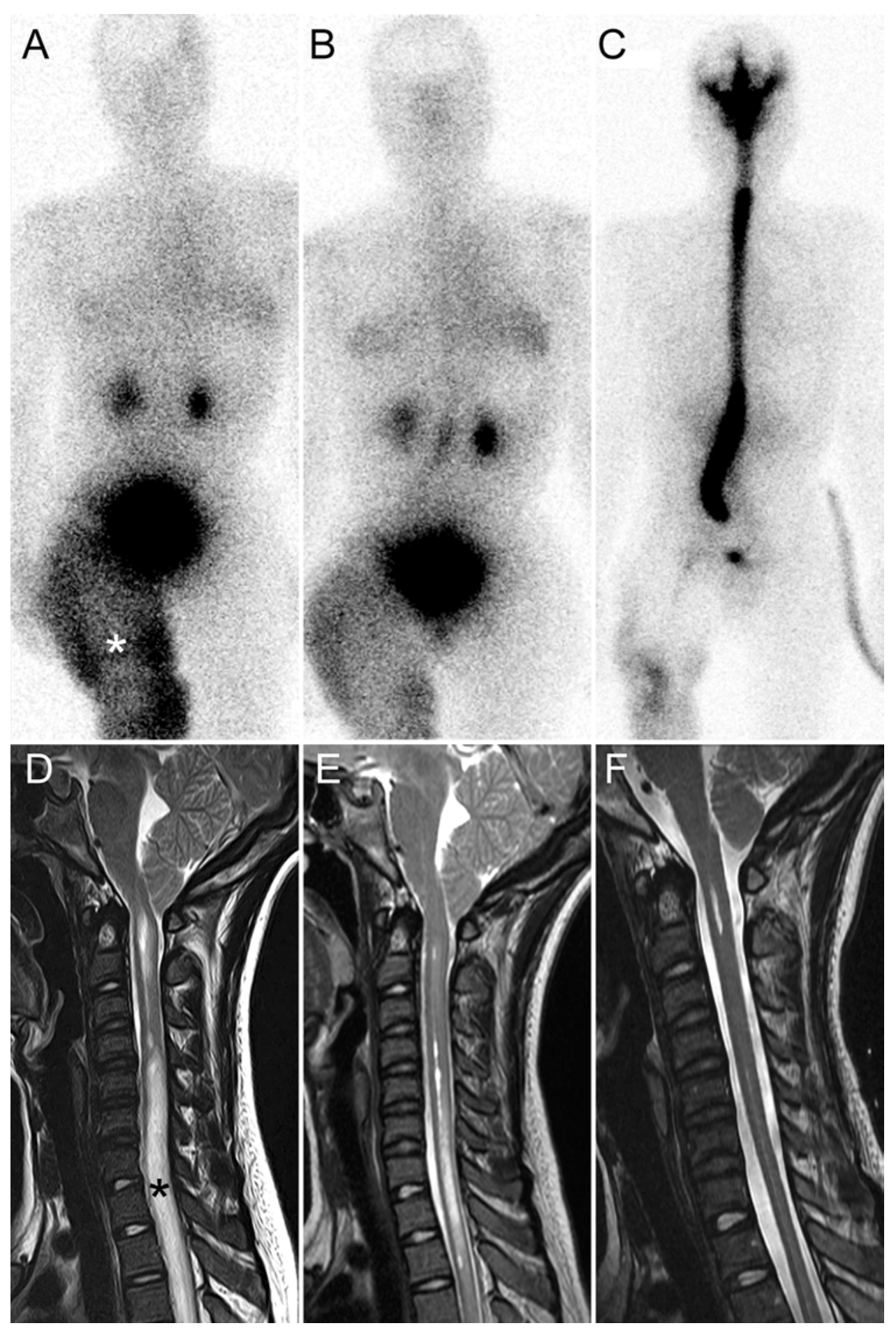

FIG. 1. A-C: Radioisotope cisterno-scintigraphy showed high uptake in the right thigh before an EBP (A, asterisk), low uptake after $\operatorname{EBP}(B)$, and no uptake after the arrest of lymphorrhea from the thigh (C). D-F: Sagittal T2-weighted MRI demonstrated tonsillar herniation and syringomyelia before an $\operatorname{EBP}(\mathrm{D}$, asterisk), a decrease in syringomyelia after the $\operatorname{EBP}(\mathrm{E})$, and the disappearance of syringomyelia after the arrest of lymphorrhea from the thigh $(F)$.

cial bone into her right femur to treat pathological fractures. At this time, she was diagnosed with angiomatosis of the bone. At age 11, she developed lymphorrhea of unknown etiology from the right thigh. At age 13, she was diagnosed with GSD based on a review of previous clinical, radiologi- cal, and histological findings. At age 15 she developed orthostatic headache; however, brain MRI showed no abnormalities. She was treated with medical therapy with interferon at another hospital. Lymphorrhea from the thigh was managed conservatively, but persisted until the age of 20 . 


\section{Intracranial Hypotension}

At age 19, she presented to the Sanno Hospital and was reevaluated because of persistent headache and motor weakness in bilateral grip strength and the left leg. Brain and cervical MRI revealed tonsillar herniation and syringomyelia. Because the headache had a postural component, intracranial hypotension was suspected. Lumbar puncture showed a low opening pressure of $5 \mathrm{~cm} \mathrm{H}_{2} \mathrm{O}$. Radioisotope cisterno-scintigraphy revealed a CSF leak from the right thigh (Fig. 1). Epidural blood patches (EBPs) were performed at the lumbar level and attenuated the CSF leak. Tonsillar herniation and syringomyelia decreased after EBPs and her motor weakness gradually recovered. She was treated with medical therapy with sirolimus at an outside hospital for 11 months. At age 20, an additional EBP was considered because follow-up MRI showed the recurrence of tonsillar herniation and syringomyelia, but was not performed because she developed a pathological fracture in the iliac bone. The fracture was treated conservatively, but it resulted in a massive abscess that required surgical debridement and antibiotics at another hospital (Fig. 2). Our patient complained of a severe headache during treatment of the pelvic abscess. The headache was not associated with the patient's head position. Her headache gradually improved after drainage of the pelvic abscess and antibiotic treatment. Lymphorrhea from the thigh completely stopped after the treatment of the abscess.

\section{Intracranial Hypertension}

At age 21, 2 months after treatment of her iliac bone, the patient presented to the Tokyo Metropolitan Neurological Hospital with severe nonpostural headache and progressive visual acuity loss. Visual acuity loss was predominantly in the right eye and recorded by counting fingers. Bilateral abducens nerve palsy was also observed. Brain MRI showed the absence of tonsillar herniation and syringomyelia. Optic papilledema was observed in both eyes, indicating intracranial hypertension. Lumbar puncture showed a very high opening pressure of $50 \mathrm{~cm} \mathrm{H}_{2} \mathrm{O}$. After lumbar drainage of the CSF, her headache improved and the worsening of visual acuity stopped. Radioisotope
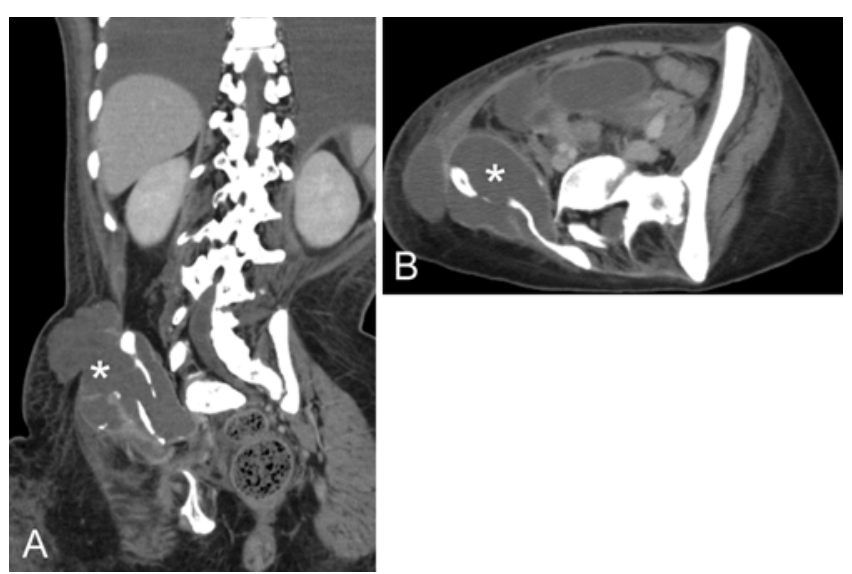

FIG. 2. Coronal (A) and axial (B) CT of the pelvis showing the fracture of the iliac bone and the abscess (asterisk). cisterno-scintigraphy revealed the complete arrest of the CSF leak from the right thigh. Medication with diuretics and acetazolamide reduced the amount of CSF draining from the lumbar level; however, headache recurred after removal of the lumbar drain. Because medical treatments did not control intracranial hypertension, a ventriculoperitoneal shunt was placed with a pressure of $17 \mathrm{~cm} \mathrm{H}_{2} \mathrm{O}$. Severe headache improved, optic papilledema decreased, and abducens nerve palsy disappeared after shunt surgery. Although mild headache persisted, intracranial hypotension or hypertension did not recur in the 1-year follow-up period.

\section{Discussion}

In the present case, we noted the following three points: 1) a CSF leak may develop not only from the osteolytic skull or spinal bone, but also from the osteolytic femur in patients with GSD; 2) the chronic low-grade CSF leak may lead to acquired CM; and 3) arrest of the CSF leak may resolve the CM.

Our literature search found only 13 patients with GSD who presented with abnormalities in CSF and intracranial pressure (Table 1). ${ }^{1-3,5,7-9,11,12,14-16,18}$ In most patients, a CSF leak was identified from the osteolytic skull base bone. There has been no case report of a patient with GSD complicated by a CSF leak from the thigh. The exact cause of a CSF fistula that extends from the spinal canal to the thigh is unknown; however, we proposed a possible mechanism as follows. Animal studies of the spinal CSF outflow demonstrated that the tracer moved from the spinal arachnoid space into the adjacent lymphatic system in the region of the spinal nerve roots. ${ }^{4,17}$ In our case of GSD, abnormal lymphatic vessels initially proliferated in the region of the pelvis and the femur. Next, communication developed between the spinal CSF cavity and the abnormal lymphatic vessels in the pelvis through the lumbosacral spinal nerve roots; after that, the CSF leakage occurred through the abnormal lymphatic vessels in the pelvis and femur. The results of radioisotope cisterno-scintigraphy clearly showed a relationship between the lymphorrhea from the thigh and the CSF leak (Fig. 1): high uptake in the right thigh indicated a direct CSF leak from the spinal canal into the thigh through the pelvis and femur.

The association between the CSF leak and CM can be explained as follows. GSD led to the development of the chronic low-grade CSF leak as described above; the CSF leak led to brain sag, including downward displacement of the brainstem and cerebellar tonsils, acquired CM developed, and CM led to the development of syringomyelia. After an EBP, the CSF leak resolved, the CM resolved, and the syringomyelia disappeared. Cases of GSD presenting with a CSF leak and CM have been previously reported, but reversible CM has never been reported., , $3,7,9^{\text {In }}$ the previous reports, patients underwent suboccipital decompression and duraplasty; however, we propose sealing of the CSF leak rather than suboccipital decompression for acquired CM resulting from a CSF leak.

Our case showed one more specific point. Among the 13 reported patients with an abnormality in the CSF in the literature, 4 showed increased intracranial pressure. ${ }^{7,11,15,16}$ 


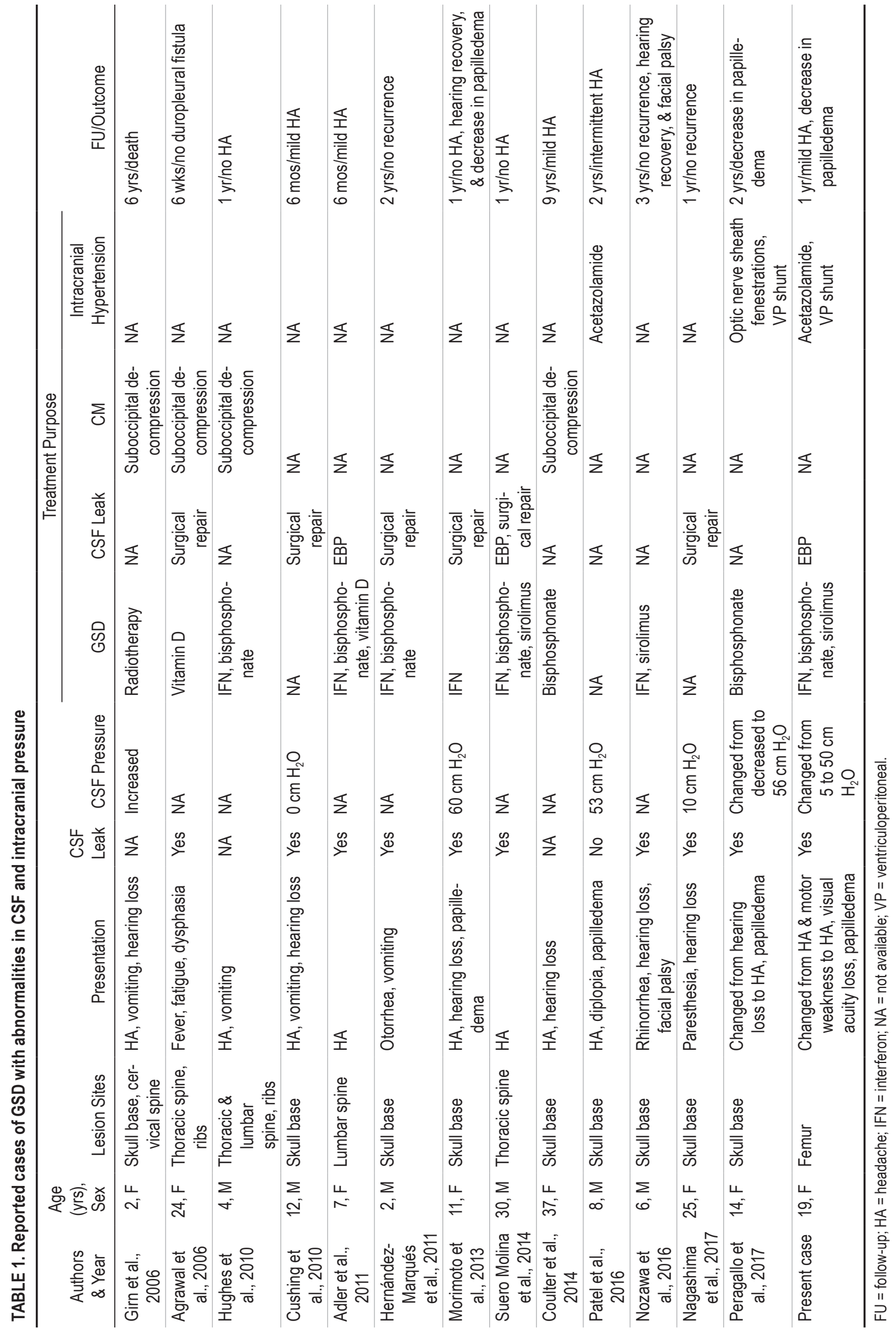


Peragallo et al. reported rebound intracranial hypertension $\left(56 \mathrm{~cm} \mathrm{H}_{2} \mathrm{O}\right)$ after the treatment of a CSF leak from the temporal bone in a patient with GSD. ${ }^{16}$ The case initially presented with intracranial hypotension and meningitis that occurred from a CSF leak. After the treatment of meningitis, the case developed intracranial hypertension. In our case, intracranial hypotension $\left(5 \mathrm{~cm} \mathrm{H}_{2} \mathrm{O}\right)$ was followed by hypertension $\left(50 \mathrm{~cm} \mathrm{H}_{2} \mathrm{O}\right)$ after the treatment of the pelvic abscess. The pelvic abscess may have affected the development of intracranial hypertension because it may have led to meningitis through the abnormal communication between the spinal canal and the lymphatic vessels in the pelvis. Because a lumbar puncture was not performed at another hospital it is not clear whether our patient had meningitis. Medical and surgical treatments for abscess in the pelvic fracture may also have affected the arrest of lymphorrhea from the thigh. A ventriculoperitoneal shunt may be the treatment of choice for these cases of intracranial hypertension.

\section{References}

1. Adler F, Gupta N, Hess CP, Dowd CF, Dillon WP: Intraosseous CSF fistula in a patient with Gorham disease resulting in intracranial hypotension. AJNR Am J Neuroradiol 32:E198-E200, 2011

2. Agrawal R, Mohammed I, Reilly PG: Duropleural fistula as a consequence of Gorham-Stout syndrome: a combination of 2 rare conditions. J Thorac Cardiovasc Surg 131:1205-1206, 2006

3. Coulter IC, Khan SA, Flanagan AM, Marks SM: Chiari I malformation associated with Gorham's disease of the skull base. Clin Neurol Neurosurg 116:83-86, 2014

4. Cserr HF, Harling-Berg CJ, Knopf PM: Drainage of brain extracellular fluid into blood and deep cervical lymph and its immunological significance. Brain Pathol 2:269-276, 1992

5. Cushing SL, Ishak G, Perkins JA, Rubinstein JT: GorhamStout syndrome of the petrous apex causing chronic cerebrospinal fluid leak. Otol Neurotol 31:789-792, 2010

6. Dellinger MT, Garg N, Olsen BR: Viewpoints on vessels and vanishing bones in Gorham-Stout disease. Bone 63:47-52, 2014

7. Girn HRS, Towns G, Chumas P, Holland P, Chakrabarty A: Gorham's disease of skull base and cervical spine - confusing picture in a two year old. Acta Neurochir (Wien) 148:909-913, 2006

8. Hernández-Marqués C, Serrano González A, Cordobés Ortega F, Alvarez-Coca J, Sirvent Cerda S, Carceller Lechón F, et al: Gorham-Stout disease and cerebrospinal fluid otorrhea. Pediatr Neurosurg 47:299-302, 2011

9. Hughes BD, Grant GA, Cummings TJ, Fuchs HE: Disappearing bone disease and Chiari I malformation. Pediatr Neurosurg 46:58-61, 2010

10. Liu Y, Zhong DR, Zhou PR, Lv F, Ma DD, Xia WB, et al: Gorham-Stout disease: radiological, histological, and clinical features of 12 cases and review of literature. Clin Rheumatol 35:813-823, 2016
11. Morimoto N, Ogiwara H, Miyazaki O, Kitamuara M, Nishina S, Nakazawa A, et al: Gorham-Stout syndrome affecting the temporal bone with cerebrospinal fluid leakage. Int J Pediatr Otorhinolaryngol 77:1596-1600, 2013

12. Nagashima H, Mizukawa K, Taniguchi M, Yamamoto Y, Kohmura E: Cerebrospinal fluid leakage and Chiari I malformation with Gorham's disease of the skull base: a case report. Neurol Neurochir Pol 51:427-431, 2017

13. Nikolaou VS, Chytas D, Korres D, Efstathopoulos N: Vanishing bone disease (Gorham-Stout syndrome): a review of a rare entity. World J Orthop 5:694-698, 2014

14. Nozawa A, Ozeki M, Kuze B, Asano T, Matsuoka K, Fukao T: Gorham-Stout disease of the skull base with hearing loss: dramatic recovery and antiangiogenic therapy. Pediatr Blood Cancer 63:931-934, 2016

15. Patel MK, Mittelstaedt BR, Valentin FE, Thomas LP, Carlson CL, Faux BM, et al: Increased intracranial pressure in a boy with Gorham-Stout disease. Case Rep Neurol 8:66-71, 2016

16. Peragallo JH, Soares BP: Vanishing act: Gorham-Stout disease leading to dynamic cerebrospinal fluid abnormalities. J Neuroophthalmol [epub ahead of print], 2017 (Letter)

17. Pollay M: The function and structure of the cerebrospinal fluid outflow system. Cerebrospinal Fluid Res 7:9, 2010

18. Suero Molina EJ, Niederstadt T, Ruland V, Kayser G, Stummer W, Ewelt C, et al: Cerebrospinal fluid leakage in Gorham-Stout disease due to dura mater involvement after progression of an osteolytic lesion in the thoracic spine. $\mathbf{J}$ Neurosurg Spine 21:956-960, 2014

\section{Disclosures}

The authors report no conflict of interest concerning the materials or methods used in this study or the findings specified in this paper.

\section{Author Contributions}

Conception and design: Takai. Acquisition of data: Takai, Yoshimoto, Takahashi, Yasui. Analysis and interpretation of data: Takai, Taniguchi. Drafting the article: Takai, Yoshimoto. Reviewed submitted version of manuscript: all authors. Approved the final version of the manuscript on behalf of all authors: Takai. Study supervision: Takai.

\section{Supplemental Information \\ Previous Presentations}

Portions of this work were presented in abstract form at the 32nd Annual Meeting of the Neurospinal Society of Japan in Osaka, Japan, on June 8, 2017.

\section{Correspondence}

Keisuke Takai: Tokyo Metropolitan Neurological Hospital, Fuchu, Tokyo, Japan.takai-nsu@umin.ac.jp. 